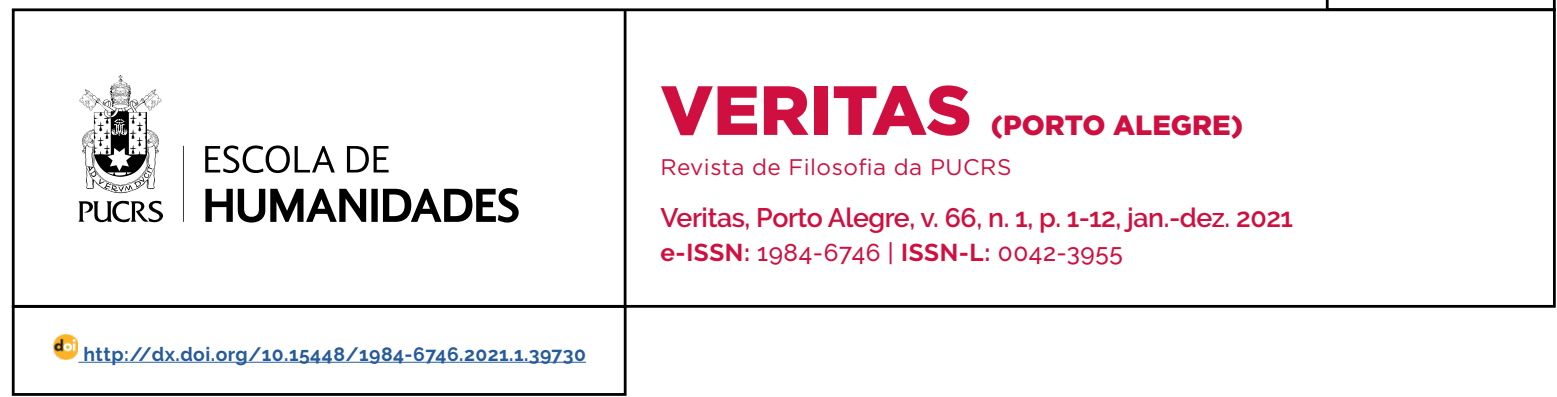

SEÇÃO: ÉTICA E FILOSOFIA POLÍTICA

\title{
Em busca de uma filosofia colonial brasileira
}

\author{
In Search of a Brazilian Colonial Philosophy \\ En busca de una filosofía colonial brasileña
}

Lúcio Álvaro Marques ${ }^{1}$

orcid.org/0000-0002-7571-0977

lucio.marques@uftm.edu.br

Recebido em: 10/12/2020

Aprovado em: 09/03/2021.

Publicado em: 07/06/2021.

\section{(c) (i)}

Artigo está licenciado sob forma de uma licença Creative Commons Atribuição 4.0 Internacional.
Resumo: Se é difícil pensar em um significado para a expressão "filosofia brasileira", pensar o que possa signficar uma "filosofia colonial brasileira" torna-se ainda mais desafiador. Para isso, necessário será justificar tanto o significado quanto o alcance da questão no periodo. Neste artigo o faremos em três passos: o primeiro situa a relação entre filosofia e colonialidade na constituição da América Portuguesa, considerando as escolas e o alcance do ensino na colônia, e traz um breve estado da arte da pesquisa; o segundo elenca os corpora philosophica provenientes dos colégios do Maranhão, Pará, Rio de Janeiro, Minas Gerais e Mato Grosso; o terceiro caracteriza as formas dos escritos, os níveis de ensino dos colégios e professores-autores e, por fim, as principais matrizes filosóficas reconheciveis nos escritos coloniais. Enfim, não obstante a dificuldade geral da questão, propomo-nos a afrontar diretamente a hipótese: o que significa uma filosofia colonial brasileira?

Palavras-chave: Escritos coloniais. Ensino superior. Colégios. Corpora philosophica.

Abstract: If it's difficult to think of a meaning to the expression Brazilian philosophy, think of what it might mean a Brazilian colonial philosophy becomes even more challenging. To this, it will be necessary both the meaning and the scope of the issue in the period. We will do it in three steps: the first one situates the relationship between philosophy and coloniality in the constitution of the Portuguese America, considering the schools and the scope of the teaching in the colony, and it brings a brief state of the art of the research; the second one lists the corpora philosophica from the colleges of Maranhão, Pará, Rio de Janeiro, Minas Gerais and Mato Grosso; and the third one characterizes the forms of the writings, the levels of the teaching in the colleges and teachers-authors and, finally, the main philosophical matrices that are recognizable in the colonial writings. So, regardless of the general difficulty of the question, we propose to confront directly this hypothesis: what does mean a Brazilian colonial philosophy? Keywords: Colonial writings. Higher education. Colleges. Corpora philosophica.

Resumen: Si es difícil pensar en un significado para la expresión filosofía brasileña, pensar en lo que puede significar una filosofia colonial brasileña se vuelve aún más difícil. Para ello, será necesario justificar tanto el significado como el alcance de la cuestión en el período. Lo haremos en tres pasos: el primero sitúa la relación entre la filosofía y la colonialidad en la constitución de la América Portuguesa, teniendo en cuenta las escuelas y el alcance de la enseñanza en la colonia, y trae un breve estado del arte de la investigación; la segunda enumera los corpora philosophica de las escuelas de Maranhão, Pará, Río de Janeiro, Minas Gerais y Mato Grosso; y el tercero caracteriza las formas de escritura, los niveles de enseñanza de los colegios y profesores-autores y, finalmente, las principales matrices filosóficas reconocibles en los escritos coloniales. Por último, a pesar de la dificultad general de la pregunta, proponemos confrontar directamente esta hipótesis: ¿qué significa una filosofía colonial brasileña?

Palabras clave: Escritos coloniales. Educación superior. Colegios. Corpora philosophica. 
Pensar o que está proposto no título do artigo supõe uma série de informações prévias. Duas delas são óbvias: a temporal, que se refere ao período entre 1500 e 1822, e a espacial, referente ao território da América Portuguessa que se chama Brasil. As outras ideias estão longe de serem óbvias, porque há pouco tempo podemos dizer algo acerca de escritos filosóficos coloniais, uma vez que se conhecia apenas um texto, datado de 1747 , com tradução pouco precisa e um comentário nada favorável (CAMPOS, 1967). Ademais, por não conhecermos outros escritos de mesmo quilate, a compreensão do ensino colonial era meramente aproximativa, e quem se dedicava a estudá-lo não fazia muito mais que elencar tendências luso-brasileiras, que, por vezes, só podiam se entrever indiretamente em alguns escritos de outras naturezas. Não se negligengia também três tendências, pouco produtivas em relação aos escritos coloniais. A primeira, reconhecivel pelo páreo "ruptura e continuismo", em que a busca de rompimento com toda a tradição europeia, sobretudo de matriz ibérica, resultaria em uma distorção canhestra de noções como identidade e formação cultural, enquanto a ilusão do continuismo subordinaria a cultura brasileira ao servilismo irrefletido, em relação a tudo o que viria de fora. Para usar uma expressão atual, o continuismo produziria a colonização epistêmica, impedindo um pensamento decolonial, isto é, autônomo. A segunda tendência prioriza a "novidade" em relação à "originalidade". O novo é um valor tipicamente cartesiano, que acreditavam ser capaz de romper com todo o conhecimento tradicional e impreciso. Não obstante, há quem identifique uma filiação teórica de Descartes, por exemplo, quanto aos Cursus Philosophicus Conimbrigensis (GOMES, 2005), atestando um indício diverso em relação à novidade pura e simples. Some-se a isso a dissolução do novo como valor, pois a própria modernidade testemunhou a derrocada do "novo" enquanto objeto de troca e como "fim da história" (VATTIMO, 2002, p. IX). Do outro lado, situa-se a busca de quem aponta em direção à origem, não ao novo. Alcançar a procedência das coisas é a condição da verdadeira originalidade, não uma simples repetição, como recentemente vimos em Marques (2020, no prelo). A terceira tendência refere-se à clássica distinção entre "sanchismo e fonsequismo": aquela supõe a predominância de uma matriz prática e pouco afeita à elaboração teórica, enquanto esta prioriza a formulação teórica, não obstante ser considerada escassa no periodo colonial, mas ambas perdem progressivamente utilidade e funcionalidade na discussão da filosofia brasileira (MARGUTTI, 2020, p. 661).

Outro elemento que merece atenção significativa é a recente retomada do debate em torno da questão da "filosofia brasileira". Sem olvidar méritos e esforços precedentes de tantos intelectuais que mantiveram, à medida do possivel, a pauta do debate, foi sobremaneira beneficiado exatamente por uma crise e consequente exclusão do currículo na Universidade Federal de Minas Gerais, a saber, eis o ponto de partida da pesquisa em filosofia brasileira de Paulo Margutti. E, de certa forma, pelo affaire entre continentais e insulares, segundo Ivan Domingues (2017). Nesse ponto, o debate atual sobre o tema recebeu novo impulso pelas obras que Margutti e Domingues the dedicaram. Seria ingênuo desconsiderá-los no estado atual da arte de nossa questão. Considerando o primeiro volume da História da filosofia do Brasil, pode-se afirmar que o saber de salvação com caráter cético-estoico-salvacionista permaneceu como distintivo do pensamento colonial, voltado, sobretudo, aos problemas específicos do país: "a conversão dos índios, a justificação da escravidão e a postura mais adequada diante do mundo a partir da experiência colonial" (MARGUTTI, 2013. p. 362). Em miúdos, esse é um pensamento capaz de caracterizar uma filosofia colonial. Entretanto, visto sob a perspectiva da Filosofia no Brasil, a conclusão, "naquele momento da primeira edição", era oposta à precedente e conservava certo ceticismo sobre o tempo em que teriamos escritores como Guimarães Rosa, Machado de Assis e Kant, nessa filosofia que, nesse tempo, dir-se-ia não apenas "no" Brasil (DOMINGUES, 2017). O derradeiro fruto desse excelente debate acadêmico (excelente tanto pela qualidade das posições demarcadas quanto pelo mérito da 
pauta proposta) revela-se promissor, pois "só com muita má vontade alguém irá ainda recusar a expressão 'filosofia do Brasil', permanecendo fiel ao enviesamento de 'filosofia no Brasil'" (MARGUTTI, 2020, p. 685). Partindo desse breve estado da arte, a pergunta que se impõe é: o que significa filosofia colonial brasileira?

A resposta à questão, por um lado, haver ou pressupor a existência de escritos filosóficos que caracterizem o objeto, e, por outro, reconhecer traços que possam, de algum modo, definir o que seria essa filosofia colonial brasileira. A resposta que propomos dar-se-á em momentos distintos: primeiro, anotaremos observações gerais sobre o periodo colonial; segundo, caracterizaremos escritos que se candidatam à estatura de corpus filosófico colonial; terceiro, delinearemos vestígios dessa possivel filosofia colonial.

\section{Filosofia e colonialidade na América Portuguesa}

O ponto de partida desta questão depende da triplice distinção precedente entre ruptura e continuismo, novidade e originalidade, sanchismo e fonsequismo. Some-se a isso a proverbial repetição sobre a existência de ensino universitário, apenas na América Espanhola, não na América Portuguesa. O que se deve esclarecer: a inexistência de universidades não significas diretamente, a inexistência de ensino superior, e a forma que a universidade colonial espanhola precisa ser matizada, tanto quanto a compreensão do que significaram os colégios coloniais, as práticas pedagógicas e os possiveis escritos resultantes dessas instituições. Por isso, pode-se perguntar diretamente: o que seriam esses escritos filosóficos coloniais brasileiros?

Essa não é uma questão retórica, pois pouco se conhece desses escritos, inclusive sobre a literatura produzida no primeiro colégio da América Portuguesa. Então, o que esperar dos demais? Eis um diagnóstico sobre o Colégio da Bahia, que, por sinal, foi o mais organizado, antigo e com melhor feição do que significa um college, na acepção anglo-saxã de que esse termo goza em nosso tempo:

\begin{abstract}
Pedro Calmon, em especifica e documentada obra sobre a vida literária baiana, escreve: "São em pequeno número os filósofos", e seus escritos, acrescentariamos, em números insignificantes. Tê-los-iamos em boa quantidade, caso não se tivessem perdido as defesas de teses de nosso Colégio das Artes. Das "conclusões públicas" de Filosofia, sobram-nos uma do Maranhão, uma do Recife, no colégio franciscano (frei Joaquim da Purificação O.F.M., entre 1789 e 1802), uma do Rio de Janeiro. Ao menos se tivesse restado o manual de Filosofia escrito por Antonio Vieira, citado já pelo Rodrigo de Arriaga!... (LIMA; CASTRO, 2006, p. 51).
\end{abstract}

Sem grande rigor, esse é o diagnóstico geral sobre a produção filosófica colonial, porém não é prudente assentir a uma afirmação geral sem considerandos. Ademais, temos razões para discordar da afirmação precedente e responder à questão relativa à "forma e origem" dos escritos filosóficos colonais. A resposta à questão implica tanto a compreensão da origem quanto da forma dos mesmos, isso porque não falamos de corpus philosophicus, mas corpora philosophica, com destaque para o plural. Naturalmente, se houveram escritos, pressupõe-se a existência de autores e colégios que os constituíram e, quanto a isso, há uma advertência inesquecivel de Serafim Leite (2006: VII, 224): "a história da cultura escolar colonial ainda não está feita em bases científicas, o que vem a significar que ainda não se estudou nas suas fontes, dentro do ambiente e dos livros que foram veículos dela". Infelizmente, a advertência do inaciano ainda não foi superada, uma vez que o Dicionário de autores do Brasil colonial, de Palmira M. R. Almeida (2010), desconhece quase a totalidade dos autores de escritos filosóficos coloniais e o Dicionário do Brasil colonial (1500-1808), de Ronaldo Vainfas (2000), sequer cita os verbetes "ensino", "universidade", "escola", "colégio" e "professor". Tais dicionários servem de índice negativo, em relação ao desconhecimento corrente sobre a forma e origem dos escritos coloniais.

Ademais, é importante recordar o que se entendia por ensino naquele periodo. As primeiras instituições de ensino lecionavam ler, escrever e contar, o que denominamos atualmente como alfabetização e letramento. Os estudos mais avançados incluíam retórica, latim, humanidades, 
filosofia e teologia. Considerando que filosofia e teologia destinavam-se, em grande parte, aos alunos internos, com finalidade de formação eclesiástica, mas também admitia externos, aqueles que, provavelmente, cursariam estudos complementares em Coimbra. Devemos lembrar, ainda, que houve demanda de vagas também para os moços pardos e indígenas e, em certo momento, a Coroa os favoreceu. Outros cursos foram requisitados para a colônia, tanto na Bahia e Maranhão quanto em Minas, mas a resposta reinol os indeferiu com base em um único argumento: recusado para "não relaxar os vínculos de dependência" (MARQUES, 2015, p. 116).

O ensino que houve no periodo colonial foi, quase sempre, com a estrita finalidade eclesiática, mas foi capaz de instruir pessoas como Antônio Vieira e Gregório de Matos. Tal educação gozou de certa distinção nos colégios principais das províncias, ou seja, nos ditos colégios "máximos" que, além dos títulos eclesiásticos, podiam oferecer os graus de bacharel, licenciado, mestre e doutor, como se afirma em relação ao Colégio Máximo do Maranhão (MARQUES, 2018, p. 99s). Aliás, tratar os títulos como eclesiásticos é quase um pleonasmo, uma vez que a Coroa delegou à Igreja a função do ensino, e os graus eram sempre legitimados pelo pontifice romano, mesmo nas universidades metropolitanas. Com isso, fica respondida a questão da origem dos escritos coloniais, mas resta esclarecer algo sobre a forma dos mesmos.

De modo geral, há cinco categorias de escritos nos colégios coloniais: a primeira constitui-se de glosas ou florilégios acadêmicos, que reúnem uma exposição de um conteúdo por aluno, que tomou notas nas aulas e as formulou em uma redação expositiva da matéria; a segunda categoria reúne alguns comentários às obras aristotélicas, sobretudo as Parva naturalia, mediante uma sequência minuciosa de teses numeradas sobre todos os livros físicos do filósofo; a terceira compõe-se de uma série bastante extensa de conclusiones que vão desde a moral, lógica, física, fisiologia (ou teoria) do conhecimento à metafísica e à teologia, e são sempre assinadas e defendidas por um aluno e um professor. Esse rito parece conferir grau acadêmico, visto que ex-alunos, depois de defender as conclusões de curso, aparecem como lentes (repetidores de um professor) em certas disciplinas; a quarta categoria reúne as teses acadêmicas ,que se distinguem das conclusiones por abordarem um conceito e explicitá-lo em relação e aplicação a todas as dimensões do conhecimento, desde a lógica, moral, física, fisiologia à metafísica e à teologia; finalmente, a quinta categoria é a dos cursus philosophicus, que se organizam em livros de lógica, fisica e metafisica, da mesma forma que os Conimbrigensis.

O ponto de maior destaque nesse momento é a constatação de que todos os escritos seguem tanto na forma expositiva quanto no conteúdo à mesma sequência lógico-argumentativa dos escritos correspondentes nas universidades metropolitanas, o que nos permite considerá-los em outro patamar de valor, não só histórico quanto teórico, para a compreensão da história do ensino colonial. Junte-se a isso uma feliz constatação: antes de 2015, reconhecia-se apenas um texto filosófico colonial, a saber, aquele traduzido por Fernando Arruda Campos, mas agora pode-se falar não só de um corpus philosophicus, mas de um corpora philosophica brasilis. Esses corporas, de fato, existem, isto é, não foram destruidos, como ainda se repete corriqueiramente. São filosóficos e precisam ser estudados, para que compreendamos aquilo que $\mathrm{S}$. Leite denomina como as bases científicas da história da cultura escolar colonial. Vejamos a seguir a constituição de tais discussões e o que podem significar.

\section{Corpora philosophica brasilis}

Os corpus que reuniremos na sequência não fazem, senão, compendiar referências e escritos, que, salvo exceções, precisam ser estudados e editados. Negar continuamente a história do ensino colonial não é um acaso, mas uma forma de apagar a incompetência dos governos em instituir ensino superior de qualidade, sobretudo depois da expulsão dos inacianos. Correntemente, a fundação das universidades brasileiras remete ao século vinte e, muitas vezes, negligenciamos 
a história dos colégios coloniais. A consequência é notória: desconhecer o passado permite a tentação de recorrer sempre ao argumento da juventude do país e das instituições e descuidar das compreensões pretéritas. Nossa intenção neste texto é, justamente, indicar elementos e documentos que atestem um pouco o que foi a história do ensino colonial.

\section{Corpus Maragnoniensis}

O conjunto de escritos que compõem esse corpus integra o Catalogus Eborensis (MARQUES, 2018, p. 135-44). Esse catálogo elenca 49 escritos, localizados na Biblioteca Pública de Évora, que se dividem em três grupos: quinze, escritos nos colégios metropolitanos; trinta, nos colégios coloniais; quatro, com origem inicialmente, e em parte, indeterminada. Excetuados os quinze primeiros escritos, certamente os demais são todos de origem colonial, redigidos no Maranhão (28 escritos) e Pará (quatro a seis escritos). O corpus em questão não é desprezivel. Na verdade, reúne 30 escritos das quatro categorias iniciais, mas não contém um cursus philosophicus. Esse corpus é proveniente do Colégio Máximo do Maranhão, que estava sob a responsabilidade dos inacianos. Esse colégio oferecia graus acadêmicos (bacharel, licenciado, mestre e doutor), desde 1709, para os alunos internos e, a partir de 1730, os mesmos títulos eram oferecidos aos externos também. Desde 1721, os escritos eram impressos, se reconhecida a qualidade quando de sua aprovação.

O corpus compõe-se de 17 glosas, e todas estruturam-se a partir de uma questão geral, discutida com bastante amplitude a partir do sentido do conceito universal em comum e em particular: o alcance semântico - o signo e o tópico - relativo ao conceito mobilizado, a resolução da questão inicial em sentido a priori e a posteriori e, finalmente, as reverberações ou conclusões relativas à filosofia natural e transnatural, vale dizer, em relação à física e à metafísica. No corpus há dez conclusiones, sendo duas de moral, uma de teologia, quatro de filosofia, duas de física e uma de fisiologia (teoria) do conhecimento. A exposição não difere quase em nada da sequência argumentativa das glosas, o que indica uma forma lógico-argumentativa comum, contendo uma definição universal: a semântica conceitual, a resolução das hipóteses teórica e prática e as conclusões físicas e metafísicas. A distinção entre as formas das conclusões segue a lógica do conteúdo. Por exemplo, as Conclusiones physiologicas estão estruturadas em seis tópicos: pro principiis corporis naturalis, et materiae primae; pro forma substantiali; pro anima, unione, et composito; pro causis in communi; pro causa materiali et formali; pro causa efficiente, finali, et exemplari. E, por fim, há quatro teses filosóficas e uma tese, lógica. Quanto às teses filosóficas, compõem-se de, aproximadamente, cento e vinte teses, ou proposições, numeradas e divididas de forma mais ou menos equivalente entre as partes. A ordem expositiva não difere em quase nada do já anunciado. Quanto à Theses logicales, com divisão em cinco partes: pro universalibus in communi; pro universalibus in specie; pro termini, et propositionis natura; pro natura, divisione, et forma syllogismi; pro signis et topicis. Enfim, reunidos e caracterizados de forma rápida e geral, eis os escritos que compõem o que denominamos o Corpus Maragnoniensis. Consideremos, por sua vez, aqueles que se referem ao Pará.

\section{Corpus Paraensis}

A existência desse corpus não se deve apenas a estar próximo ao anterior, nem pela razão de serem encontrados juntos na biblioteca de origem. Embora não seja muito extenso, o fato de haver escritos provenientes do Pará prova que o desenvolvimento nas regiões Nordeste e Norte não foi desigual. O colégio do Norte constituía a grande universidade das almas, segundo Vieira (apud LEITE, 2006, p. VII), e desenvolveu-se concomitante ao do Maranhão, porém, os escritos paraenses trazem marcas próprias. Em primeiro lugar, cumpre lembrar que o Pará não foi considerado colégio máximo por estar associado à Província do Maranhão. Não obstante, existem de quatro a seis textos escritos naquelas paragens. Em segundo lugar, não está relacionado a escritos inacianos, mas carmelitas. A expansão e distribuição dos 
colégios não foi exclusividade de uma ordem, e não nos admiremos de reconhecer, em algum momento, a presença e colaboração de professores de diferentes ordens em um mesmo colégio. Em terceiro lugar, os escritos paraenses talvez tragam uma marca distintiva, que é a relação direta com a realidade dos povos originários e africanos, pois voltam-se aos temas de filosofia moral.

Há dois escritos assinados por Emmanuel da Sylva: um impresso e o outro não. Ambos parecem redigidos na forma jesuítica, mas o impresso apresenta uma dedicatória ao áureo trono paraensis e está registrado como defendido na felicior hora a' Carmeli, o que, talvez, indique sua origem ou, pelo menos, a relação direta entre os dois colégios e os respectivos professores e superiores gerais. Essas informações preliminares são só uma provocação quanto à necessidade de os estudar e formalizar as relações. Ambos são glosas filósoficas, com uma diferença em relação aos anteriores: o manuscrito tem nove laudas, regididas com caligrafia bastante pequena, e o impresso possui 12, o que é completamente distinto do maranhense.

O segundo texto traz uma identidade precisa: o local do escrito é o Grão-Pará, no Colegio Carmeli Paraensi Conventu, e trata-se do texto Conclusiones theologicas de ineffabile incarnationis mysterio, que difere tanto pelo conteúdo quanto pela forma. Apenas para exemplificar, a questão debatida é Conueniente tempore facta fuit incarnatio? A exposição compõe-se de quatro conclusões: "pro possibilitate existentia et conuenientia incarnationis, pro motivo seu causa finalis incarnationis, pro termino assumente et assumpto tam de facto quam de possibili" e "pro unione hypostatica". A forma de exposição das conclusões evidencia a distinção em relação às conclusões filosóficas, isso é, a lógica distingue-se da teológica, e essa conclusão permite compreender algo que, para os apressados, parece pouco distinto: a separação entre metafísica e teologia. A conclusão mostra, nesse sentido, o rigor do ensino nesses colégios, em um tema caro ao franciscanismo.

O terceito escrito em destaque também se assemelha ao primeiro, já assinalado. No caso anterior, digo que podem ser uma ou duas glosas filosóficas. Nesse caso, talvez haja a mesma coincidência e, então, seriam duas conclusões morais. Esses são os únicos escritos a tratar questões morais e têm particularidades comuns: são manuscritos, não têm a folha de rosto e não consta o nome dos autores em nenhum lugar. No caput da primeira lemos "Conclusiones morales pro servitute" e da segunda, "Conclusiones morales pro injuriis". Essa, é ainda não estudada, mas traz as mesmas características da primeira, por isso a hipótese de ambas serem paraenses. O conteúdo refere-se aos crimes de infâmia e detratação de honra em falsos testemunhos públicos: as injúrias públicas. A segunda conclusão foi publicada recentemente em "Escritos sobre escravidão", pois trata essa questão no âmbito das discussões do século XVIII:

\begin{abstract}
[...] primeiro, as Conclusões morais sobre a escravidão datam do início do século dezoito, no máximo; segundo, a referência "há menos de três anos um sábio Religioso" faz pensar, por óbvio, naquele inaciano que tinha livre trânsito na colônia e que aí viveu entre 1608 e 1697 - Antônio Vieira (...) Quanto às Conclusões morais sobre a escravidão, o anonimato torna-se duplamente suspeito, tanto por criticar uma condição tão séria em tempos coloniais quanto por se referir ao sábio religioso se se trata de uma crítica a Vieira, não obstante, escrito no Convento Carmelita do Pará. Por essas razões, atribuímos o escrito a um Anonymous Paraensis e, dada essa condição, não temos como oferecer mais dados biográficos que os conjecturados até aqui. Deixando de lado as questões de datação, autoria e identificação da crítica, o manuscrito inédito compendia elementos interessantes quanto aos argumentos antiescravistas que figuram, em parte, como moeda comum no período, além de estabelecer uma quádrupla classificação da escravidão, o que não vimos em outros textos. Não obstante a brevidade (quatro laudas em dois fólios, conforme o manuscrito da Biblioteca Pública de Évora, Fundo dos Reservados, Códice CXVIII/1-1, fólios 171r-172v), o manuscrito apresenta argumentos completos e relativamente bem formulados. A grafia é clara e inclui notas e correções às margens, bem como um "estudo de caso" (casus extremum) que compõe sua parte final. (MARQUES; PEREIRA, 2020, p. 25).
\end{abstract}

Há, ainda, pelo menos, dois comentários aos livros físicos (Parva naturalia) de Aristóteles e, neles, os autores percorrem todos os livros do Estagirita com formulações em teses numeradas, 
que se estruturam na sequência: "pro mundo, et elementis"; "pro caelis"; "pro metheoris; pro animae suplementis, seu parvis naturalibus"; "pro motu, loco, vacuo, tempore, continuo et infinito"; "pro generatione, et corruptione". O estado de conservação dos comentários não é o melhor, mas ainda é possivel editá-los, desde que o leitor separe as formulações filosóficas das contas matemáticas e listas que constam nas margens.

Talvez nem todos esses escritos sejam do Colégio Paraense, mas os Comentários às obras fisicas de Aristóteles apresentam as mesmas características das Conclusões morais e, por isso, à medida que forem estudadas, a evidência da origem se manifesterá. Afinal, antes de realizar estudos rigorosos, qualquer conclusão é temerária. Outro corpus a ser considerado refere-se aos colégios fluminenses, que veremos em sequência.

\section{Corpus Fluminensis}

Esse corpus é curioso, uma vez que se tratava do único escrito filosófico de todo o periodo colonial. Felizmente, esse não é mais o caso. A primeira leitura que fizemos das Conclusiones metaphysicas de ente reali foi durante os estudos de graduação. A leitura da tradução feita por Fernando Arruda Campos (1967) despertou a curiosidade por compreender as razões de haver apenas um exemplar em todo o periodo colonial. Porém, as tentativas de estudar o original esbarravam na dificuldade de acesso. A retomada e um estudo desse texto aconteceram quase cinco décadas depois. Essas Conclusiones foram assinadas pelo professor Francisco de Faria e pelo aluno Francisco Fraga e impressas na tipografia de Antônio Isidoro da Fonseca em 1747. O escrito é breve, constando uma dedicatória ao mecenas que financiou os estudos do aluno e as três conclusões sobre o tema em pauta. Em 2015, foi editado e traduzido todo o texto, quando se reconheceram algumas omissões feitas pelo primeiro tradutor (CAMPOS, 1967), além de se fazer uma nova interpretação, menos equivoca que a precedente. Onde Campos identificou um ecletismo tardio e canhestro, depois de cotejar citações escotistas, o tradutor identificou uma clara filiação ao mestre franciscano, não uma leitura eclética tardia (MARQUES, 2015). O escrito abriu as portas para novas pesquisas.

Os corpus maranhenses e paraenses foram localizados graças às pesquisas desse exemplar fluminense. E, felizmente, o Corpus Fluminensis ainda tem outros escritos a serem pesquisados. Aliás, essa é uma constatação comum a todos os corpus que apresentaremos. Não há dúvida de que muito já foi perdido pela má conservação dos arquivos, embora seja possivel preservar o que resta em formato digital. Não se trata de apenas digitalizar e pôr à disposição pública. Esses escritos precisam ser estudados, para que compreendamos, na verdade, a história dos colégios e dos professores que os criaram. O conteúdo não é o primordial a ser analisado, antes disso, precisamos buscar e reconstruir a história negada e silenciada do ensino no período colonial.

O corpus em questão traz possibilidades ainda mais arrojadas, pois não se trata apenas de escritos jesuíticos, bem como o paraense. Neste, incluem-se escritos de mestres beneditinos, até então bastante desconhecidos. Quanto ao mais, esse é um campo que não exploramos em quase nada, e o catálogo é promissor: Universa Philosophia Scholastica in logicam, physicam ac metaphysicam, do Pe. Antônio da Silva (1732-1735); Cursus Philosophicus Secundus, do Frei Antônio de São Bernardo OSB (1740-1742); Institutiones Philosophiae ecclesiasticae pars prima, do Frei José S. da Natividade (1770); Philosophia Iscoltiorium philosophia collecta, do Frei João do Apocalipse OSB (1769).

O que esse catálogo sugere? Nada menos que a quebra do paradigma negacionista, que se recusa a admitir que houve ensino colonial com relevância destacada e que esse ensino precisa ser estudado, de forma sistemática, para compreendermos o alcance da filosofia colonial, além de conhecer o que foram as instituições de ensino do período. $O$ dito é suficiente para o momento. Além disso, ainda restam outros corpus que merecem atenção e rigor da pesquisa. Caminhemos da praia às montanhas. 


\section{Corpus Caracensis}

Da praia à montanha, o caminho é íngrime e acidentado, mas tem suas belezas. O percurso feito a pé ou em lombo de burros demorava um bom tempo e não teria feito menos que o imaginado por nós, que, atualmente, podemos percorrer os $600 \mathrm{~km}$ de forma confortável em um dia. As Minas são muitas, e os Gerais estendem-se para além dos olhos. No coração do ciclo do ouro e dos diamantes, encravaram-se dois colégios, cuja história seria tão bela quanto promissora. Aquele dedicado à Senhora da Boa Morte, sede do bispado, formou gerações de intelectuais, que atuam nas mais variadas frentes, si non è vero è ben trovato, inclusive Geraldo Viramundo, romanceado por Fernando Sabino em O grande mentecapto. 0 caminho da praia à montanha é lento e escarpado:

Em junho de 1811, depois de ficar um tempo em casa com a família, Viçoso entrou para a Congregação da Missão (Lazaristas) para completar os estudos até ser ordenado sacerdote em 7 de maio de 1818. Após a ordenação, foi enviado para ensinar filosofia no Real Colégio de Nossa Senhora da Purificação em Évora, ficando ali pouco tempo, pois em 27 de setembro de 1819, a pedido de D. João VI que solicitou missionários aos Lazaristas para catequizar povos na capitania do Mato Grosso, Viçoso, juntamente com o Padre Leandro Rebello Peixoto e Castro, iniciaram a viagem para o Brasil. Depois de uma longa viagem, que durou mais de dois meses, em 7 de dezembro de 1819, os dois missionários chegaram ao Rio de Janeiro. Alí receberam a notícia de que iriam para a Casa do Caraça, em Minas Gerais. Percorreram aproximadamente 600 quilômetros, chegando à Serra do Caraça em 15 de abril de 1820. Paralelo às atividades missionárias desenvolvidas na região, os dois religiosos abriram em 1821 um colégio no Caraça. (MARQUES; PEREIRA, 2020, p. 26-27)

O caminho seria da praia ao sertão, isto é, ao Mato Grosso, mas as montanhas os prenderam a meio caminho. Se não chegaram ao sertão matogrossense, chegaremos em busca do corpus redigido naquelas terras. $O$ esplendor da serra do Caraça encantou os dois religiosos, ao passo que os costumes fascinaram Peixoto e Castro. A lei e a política eram os norteadores da missão de Viçoso. O primeiro manuscrito que saltou-nos aos olhos foi encontrado pelo professor João Paulo Rodrigues Pereira e trata-se de um escrito que reúne uma sintese de um folheto escravista, redigido por Peixoto, e Castro e que foi discutido e criticado minuciosamente por Viçoso em Escravatura ofendida e defendida (1840), cujo foco é a discussão da lei de 1831. O humanismo de Viçoso faz-se notar desde as primeiras linhas, e o autor usa todos os argumentos que lhe pareciam plausiveis para deslegitimar as ditas razões da escravidão. O texto que estava desaparecido há tempos foi publicado recentemente (MARQUES; PEREIRA, 2020, p. 145-203).

Em Minas, há três arquivos que ainda não foram pesquisados suficientemente, a saber: aquele do Caraça, outro em Mariana e o Arquivo Público Mineiro. Não por acaso, ainda não se sabe em que gaveta estão escondidas as Theses Philosophicae de Logica et Metaphysica, impressas na Tipografia de Silva, em Ouro Preto, no ano de 1828. Descobrir uma tese, ainda que pouco posterior ao fim do periodo colonial, indica, não só a existência de um círculo de trabalho mais ou menos comum, como vimos em relação ao Maranhão, Pará e Rio de Janeiro, mas também a certeza de que o ensino e a produção desse tipo de escritos foram práticas difusas nos colégios. Quanto à origem, essas Theses foram escritas no Colégio do Caraça, mas deve-se pesquisar, também, possiveis escritos do Colégio do Seminário de Senhora da Boa Morte, em Mariana. Quanto a essas Theses e à praxe pedagógica no Colégio do Caraça, cumpre ressaltar o valor expresso nessas palavras de Carrato:

Esses "artianos" (estudantes de filosofia) - in Imperiali Seminario ejusdem Facultatis auditores, isto é, auditores ou monitores do curso de filosofia no Imperial Seminário do Caraça - prepararam seus trabalhos e fizeram a disputatio em latim, sob a direção do Prof. Joaquim Antão Fernandes Leão (que viria a fazer uma bela carreira de homem público, no Segundo Império). Foi uma solenidade esplêndida (in hora solemni), realizada no recinto da capela de Nossa Senhora Mãe dos Homens, no dia 20 de julho de 1828, perante numeroso público, especialmente convidado, constituindo-se no ato final de encerramento do ano letivo. No Prooemium do folheto-convite da solenidade - cujo título é Theses Philosophicae de Logica et Metaphisica - vazado em latim até razoável, sente-se uma aura iluminista, quase kantiana, nesta passagem: Anima nostra, naturali felicitatis desiderio, quo pollet, se quasi invita in veritatis in- 
quisitionem vergit, et nos nunquam medium aptius reperiri nullo negotio videmus, quam cognoscendi facultatem excolere, cum per Logicam, tum per Metaphisicam. Se a generosa alma dos jovens auditores caracenses é levada à investigação da verdade, pelo desejo natural da felicidade, êles não irão achar nenhum outro meio mais eficaz para isso, e para tôdas as outras coisas, do que cultivarem a faculdade do conhecimento, seja pelos caminhos exatos da Lógica, seja pelos da ciência metafísica, já que qualquer futuro estudo da suprema Teologia, sua meta final, e, mesmo, da Filosofia Moral, tanto em voga na época, haveria de requerer o domínio das regras claras da arte logística. Sôbre êsses pressupostos formacionais é que se assentará tôda a obra educativa do Caraça, em relação aos seus escolásticos que se destinam ao sacerdócio e aos próprios colegiais leigos que começam a encaminhar-se para as primeiras Academias de Direito (São Paulo e Olinda), que estão sendo fundadas. (CARRATO, 1968, p. 119)

Não é tempo de discutirmos a aura iluminista identificada por Carrato, mas não é menos verídico o apego escolástico e a confiança na racionalização do mundo. Por agora, cumpre destacar que os arquivos mineiros ainda nos reservam muitas possibilidades. Torpe seria desprezar o Caderno de anotações sobre transformismo ou darwinismo, o Caderno de anotações de filosofia (1904), o Caderno de meditações (1954), o De modestia e, sobretudo, o Regulae Scholasticorum (1807), que é, nada menos, que o guia pedagógico da Congregação da Missão.

O que se reconhece nos três arquivos mineiros é uma fonte parcamente explorada e largamente desconhecida. O Arquivo Público Mineiro é um nobre e rico desconhecido e não menos, os outros citados. Ainda não temos certeza, por isso não elencamos outros escritos desses colégios. Temos indícios de existência, o que significa que a pesquisa precisa ser levada adiante. E, como dissemos anteriormente, o caminho não foi apenas da praia às montanhas, mas estendeu-se ao sertão, conforme nomeado em alguns documentos. Eis o tempo de seguirmos caminho em direção ao Mato Grosso e conhecer novas paragens.

\section{Corpus Serenensis}

Encontrar um manuscrito é uma surpresa tão grande quanto maravilhosa. Rodrigo Homem, por exemplo, era um desconhecido que, se- gundo Serafim Leite (2006), teria escrito três Conclusiones nas terras maranhenses e, depois de algumas pesquisas, agora sabe-se que são sete textos e que o professor ou "lente" Rodrigo Homem lecionou, isto é, leu um curso filosófico entre 1720 e 1725 no Maranhão e teve uma breve passagem pelo Pará, antes de retornar a Lisboa. Nesse sentido, estudar um manuscrito é descobrir um pouco da história e dos costumes de um povo e ver nascer um escritor diante dos nossos olhos. Menor não foi a surpresa ao encontrar os textos referentes ao tal Colégio Serenense do Mato Grosso. Inicialmente não causou surpresa maior o fato de haver escritos nesse Estado, mas, quando soube da extensão, veio a surpresa. Ademais, isso não é de menor importância, trata-se do primeiro lugar em que localizamos um Cursus Philosophicus completo no Brasil. Contra certas opiniões, que insistem em afirmar que não houve escritos sistemáticos na colônia e que foram todos destruídos na expulsão dos jesuitas, não somente existem quanto são de máxima relevância. Eis uma catalogação dos mesmos, quando mencionados outrora por Marques:

[1] Franciscan manuscripts, originating from the Serenense College, alias Matto Grosso, by Fr. Emanuelle ab Angelis (Porto, BPM Ms. 380), initiated in November 25th 1756, constituted by three parts. The first contains Logic and ends praising to Our Lady, Saint Francis and Saint Anthony, patron of the College. The second contains Physics. The third contains the three De Anima books: Alunus Provinciae Nostrae in Nostro Colegio Serense, vulgo Matto Grosso, Inceptum die 25 Novembris de 1756 A. Acceptum a Fr. Emanuele Ab Angelis inipsa Provincia Actalis Colega.

[2] Porto, BPM Ms. 936, including Logics: Philosophiae Peripateticae Integer Cursus Ad Mentem Subtilissimi D. Joanis Duns Scoti Elaboratus A Fratre Emmanuele a Sta. Anna Artium Lectore Acceptus A Fratre Antonio a Jesu In Hoc Divi Antonii Serenense Cenobio ab Anno 1759 usque ad Annum 1762.

[3] Porto, BPM Ms.930: Tractatus Primus de Phisica Generali, continuation of the previous manuscript, also by the same author, 1761-1762. (MARQUES, 2018, p. 146).

Desde que tomamos conhecimento dessas referências, reiteramos o esforço de ler e compendiar os escritos coloniais. Os corpus elencados são uma primeira mostra do que está por vir. 
Sabemos de outros escritos presentes em São Paulo, por exemplo, mas ainda não temos como integrá-los a este artigo². O que registramos sobre a possivel história do colégio que produziu o manuscrito é apenas um indício da desconfiança com que se olha para os mesmos. Felizmente, existem, também, outros pesquisadores que não duvidam dos promissores resultados que podem advir dessas pesquisas, como afirma Margutti (2020). E, com isso, retornamos à questão inicial: o que significa filosofia colonial brasileira?

\section{Uma filosofia em construção}

Eis o momento de delinear o que poderia ser uma filosofia colonial brasileira. A carência de estudos sistemáticos sobre esses e outros colégios e corpus limita o possivel desenho de linhas gerais dessa filosofia. O que há são vestígios e hipóteses interpretativas iniciais, que propomos como desafio e horizonte programático neste artigo.

Em primeiro lugar, os escritos dos corpora são variados e, ao mesmo tempo, ricos nas formas. Alguns são trabalhos acadêmicos, destinados ao exercício de repetição e às anotações de aulas, o caso das glosas. As conclusões são escritos de conclusão de curso e reúnem textos de diversas áreas da filosofia, da moral e da teologia. Nessas conclusões de moral, destaca-se um ponto fundamental, que é, justamente, a relação do conhecimento com a realidade nacional e a coragem de criticar o sistema social e político vigentes. As teses são a versão consumada e ampliada das conclusões, pois conferiam graus superiores (mestre ou doutor), como é o caso de Bento da Fonseca, que estudou no Maranhão, teve como orientador Rodrigo Homem e, depois, tornou-se lente, substituindo o antigo mestre. Os comentários são escritos muito interessantes e altamente rigorosos, pois sumarizam as obras físicas de Aristóteles, em forma de teses, que estão dispostas nos dois exemplares de forma numérica e na sequência presente na obra do
Estagirita. E, finalmente, os cursus philosophicus não deixam dúvidas quanto ao alcance e similaridade entre as produções de colégios reinóis e coloniais, tanto pela extensão (em média, têm entre 400 a 871 fólios) quanto pela complexidade e lógica argumentativa (trazem a lógica, a física e a metafísica). Com isso, e considerando o número de escritos elencados, seria imprudente e improdutivo negar o sentido de estudar tanto a história dos colégios coloniais quanto os escritos e conseguintes autores, com vistas a compreender a forma e alcance do ensino colonial.

Segundo, o catálogo que apresentamos está longe de ser exaustivo e baseia-se em pesquisas a que tivemos acesso, mas, graças aos nossos estudos atuais, sabemos que é possivel ampliar tanto os escritos de corpora, já elencados, quanto estender a outros corpus e colégios, que ainda estamos sistematizando. Os escritos que compõem esses corpus não estão reunidos em um ponto único, ou melhor, em apenas uma biblioteca. É necessário tatear, escrutinar as diversas bibliotecas nacionais, brasileiras e lusitanas, com vistas a localizar, catalogar, editar e estudar outros exemplares desconhecidos até o momento. Quanto aos colégios e aos autores desses escritos, necessário se faz, por um lado, estudar as histórias individuais, porque as informações disponiveis são, ainda, imprecisas e escassas e, por outro lado, se ainda não conhecemos os colégios, que se dirá dos autores! Antes, já havíamos mencionado Almeida (2010) e Vainfas (2000) e essa constatação não é menor, pois o desconhecimento de colégios condena ao silêncio, igualmente autores e professores. O desconhecimento é talvez a grande causa do negacionismo de nossa história do ensino.

E, em terceiro lugar, é necessário mencionar as referências teóricas presentes nos corpora philosophica, que compendiamos em quatro eixos:

i) em que se faz evidente o apreço pelo escotismo geral nos escritos coloniais,

\footnotetext{
2 O máximo que sabemos é que se trata de um escrito de Frei Gaspar da Madre de Deus (Gaspar Teixeira de Azevedo, 1715-180o), organizado em dois volumes manuscritos, respectivamente, voltados à lógica e à física e que tem como título geral Philosofia Platonica seu Cursus Philosophicus Rationalis. Os artigos de Carlos Lopes de Mattos:MATTOS, C. L. Frei Gaspar da Madre de Deus. Revista Brasileira de Filosofia. v. XX, fasc. 78, 1970, p. 222-225; Mattos, C. L. Trechos de Frei Gaspar da Madre de Deus. Revista Brasileira de Filosofia. v. XXII, fasc. 85, 1972, p. 70-86; Antônio Paim (1998, p. 8-21) apresentam um abstract do texto, que, primeiramente, merece ser estudado.
} 
ou seja, nas conclusiones, teses e cursus philosophicus encontram-se menções diretas e citações literais e extensas do franciscano. O pensamento subjacente aos mesmos não se reduz às citações de conceitos de uso típico escotista, mas as concepções filosófica e teológica são claramente escotistas;

ii) a presença de Tomás de Aquino soaria bem mais notória e plausivel considerando o Ratio Studiorum e a conseguinte pedagogia. Nesse aspecto, o mesmo se aplica a Aristóteles. A leitura do Estagirita está, quase sempre, filtrada pelos comentários escotista e tomista nas glosas, conclusões e teses. Apenas nos comentários e nos cursus philosophicus o Estagirita é lido e citado diretamente e, nesses casos, cumpre destacar que não se trata, salvo engano, de escritos inacianos, mas beneditinos e franciscanos;

iii) há um uso preciso dos mestres ibéricos no debate da escravidão. Penso nas conclusões morais que mencionam, direta e indiretamente, conceitos presentes nas universidades ibéricas e nos principais autores que trataram da questão. Além disso, tanto nestas quanto nos outros escritos, há citações com uma erudição interessante, que vai de Esopo a Ovídio e Cícero e mais, quanto à lógica, Porfírio e Boécio sempre são requisitados;

iv) finalmente, há menções a conceitos e autores da era moderna. Naqueles, é mais fácil distinguir os avanços quanto à modernidade e os novos horizontes do conhecimento. Nestes, (os autores modernos), são citados, até Bacon, Descartes, Gassendi e Vico. Enfim, autores que se faziam notórios ao humanismo ilustrado dos professores das grandes universidades do Velho Mundo.

Com isso, a pergunta sobre o significado da filosofia colonial brasileira talvez não tenha, ainda, uma resposta pronta, mas cremos, sinceramente, que o tempo de duvidar de existência e pertinência no horizonte dos estudos históricos, educacionais e filosóficos brasileiros já passou, exceto aos recalcitrantes. A resposta incompleta deve-se tanto ao caráter processual da pesquisa quanto à necessidade de estudos mais amplos, para bem avaliar os avanços mediante as edições de escritos coloniais. Enfim, a existência desses corpora indica, antes de mais nada, que o desconhecimento que pesa sobre tais integra a política do esquecimento, que vige sobre a cultura e a história nacional. Se ainda não está pronta a resposta, é questão de tempo, e, como se diz, resultará desse opus in progressu.

\section{Referências}

ALMEIDA, P. M. R. Dicionário de autores no Brasil Colonial. $2^{\mathrm{a}}$ Ed. Lisboa: Colibri, 2010

CAMPOS, F. A. Uma disputa escolástica no século XVIII. Documentário de filosofia no Brasil. Revista Brasileira de Filosofia, v. XVII, p. 203-208, 1967.

CARRATO, J. F. O ensino do latim no Colégio do Caraça. Revista de História, v. 37, n. 75, p. 105-127, 1968. Disponivel em: http://www.revistas.usp.br/revhistoria/article/ view/128467. Acesso em: 28 /8/2020.

DOMINGUES, I. Filosofia no Brasil. Legados e perspectivas. São Paulo: UNESP, 2017.

GOMES, J. P. Os Conimbricenses. Lisboa: Guimarães, 2005.

LEITE, S. História da Companhia de Jesus no Brasil VII. Belo Horizonte: Itatiaia, 2006.

LIMA JR., F. P.; CASTRO, D. A. B. História das idéias filosóficas na Bahia (séculos XVI a XIX). Salvador: CDPB, 2006.

MARGUTTI, P. História da filosofia do Brasil (1500-hoje): $1^{\text {a }}$ parte: o periodo colonial (1500-1822). São Paulo: Loyola, 2013.

MARGUTTI, P. História da filosofia do Brasil (1500-hoje): $2^{\mathrm{a}}$ parte: a ruptura iluminista (1808-1843). São Paulo: Loyola, 2020.

MARQUES, L.A.; PEREIRA, J. P. R. Escritos sobre escravidão. Porto Alegre: Fi, 2020.

MARQUES, L.A. A lógica da necessidade: o ensino de Rodrigo Homem no Colégio do Maranhão (1720-1725). Porto Alegre: Fi, 2018.

MARQUES, L.A. Philosophia brasiliensis: história, conhecimento e metafísica no periodo colonial. Porto Alegre: Fi, 2015.

MARQUES, L.A. The Jesuitical philosophical heritage in Brazil. Massachusetts: Boston College, 2020 (no prelo).

MATTOS, C. L. Frei Gaspar da Madre de Deus. Revista Brasileira de Filosofia, v. XX, fasc. 78, p. 222-5, 1970

MATTOS, C. L. Trechos de Frei Gaspar da Madre de Deus. Revista Brasileira de Filosofia v. XXII, fasc. 85, p. 70-86, 1972. 
PAIM, A. Etapas iniciais da filosofia brasileira. Vol. III. Londrina: UEL, 1998.

VAINFAS, R. Dicionário do Brasil colonial, 1500-1808. Rio de Janeiro: Objetiva, 2000

\section{Lúcio Álvaro Marques}

Doutor em Filosofia PUCRS. Professor Adjunto na Universidade Federal do Triângulo Mineiro (UFTM).

\section{Endereço para correspondência}

Lúcio Álvaro Marques

Edifício do Centro de Pesquisa Dr. Aluizio Rosa Prata, Sala 535

Av. Getúlio Guaritá, 159

Abadia, 38025440.

Uberaba, MG, Brasil

Os textos deste artigo foram revisados pela Zeppelini Publishers e submetidos para validação do(s) autor(es) antes da publicação. 